\title{
EL MONOCULTIVO OLIVARERO JIENNENSE: CONFORMACIÓN HISTÓRICA, VALORES PATRIMONIALES Y PROYECCIÓN CULTURAL-TURÍSTICA
}

\author{
José Domingo Sánchez Martínez ${ }^{1}$ \\ Universidad de Jaén \\ Antonio Ortega Ruiz ${ }^{2}$ \\ Universidad Internacional de Andalucía
}

\section{RESUMEN}

Se presentan algunas características básicas del monocultivo olivarero existente en la provincia de Jaén, tales como su alcance superficial y las claves que han marcado su expansión reciente. De la misma forma, se describe la diferente realidad paisajística, agronómica y económica que subyace bajo la aparente uniformidad que concede la existencia de un impresionante y continuado tapiz arbustivo. Con posterioridad, se repara en la capacidad que el olivar ha tenido para generar múltiples elementos de carácter patrimonial, al objeto de analizar finalmente las iniciativas que se están llevando a cabo para promover la difusión de sus valores culturales y el aporte que pueden significar para un aprovechamiento multifuncional en los territorios donde su presencia es masiva.

Palabras clave: Andalucía; olivar; aceite de oliva; patrimonio agrario; oleoturismo; paisaje cultural.

Recibido: 8 de enero de 2015

Devuelto para su revisión: 21 de abril de 2015

Aceptado: 15 de junio de 2015

1 Departamento de Antropología, Geografía e Historia. Universidad de Jaén. Campus Las Lagunillas. 23071 JAËN (España).E-mail: jdsanche@ujaen.es

2 Centro Andaluz de Estudios para el Desarrollo Rural. Universidad Internacional de Andalucía. Palacio de Jabalquinto. Plaza de Santa Cruz, s/n. 23440 Baeza. JAÉN (España). E-mail: a.ortega@unia.es 


\title{
The olive monoculture of Jaen: historical structure, heritage values and cultural-touristic importance
}

\begin{abstract}
We consider some basic features of the existing olive monoculture in the province of Jaén, such as their surface scope and the keys that have marked its recent expansion. Likewise, the different landscape and economic reality underlying the apparent uniformity granting the existence of an impressive and continuous shrub skin. Subsequently, we repaired in the capacity that olives has had to generate heritage, in order to analyze the initiatives being undertaken to promote the dissemination of cultural values and the impact they can mean to a multifunctional use in territories where its presence is massive.
\end{abstract}

Keywords: Andalusia; olive tree; olive oil; agricultural heritage; turism; cultural landscape.

\section{INTRODUCCIÓN}

Una combinación de potentes razones fisiográficas y económicas explica la extraordinaria dimensión que el cultivo del olivar ha alcanzado en el Sur de España. Como resultado de una expansión superficial que no ha parado desde los albores de la Modernidad, y que resultó especialmente intensa durante determinadas coyunturas históricas favorables, en la actualidad ocupa 1,5 millón ha (el 30\% de la superficie agrícola). Es por ello, que se le ha calificado como el principal paisaje de la Comunidad Autónoma de Andalucía (Guzmán y Zoido, 2013).

La realidad que se encuentra tras un análisis atento de ese inmenso tapiz, de gran continuidad sobre todo en el centro de la región, es de una enorme heterogeneidad. No cabe hablar en realidad del paisaje del olivar sino, más propiamente, de los paisajes olivareros andaluces. Y es que, ya sea atendiendo a razones como la antigüedad y el marco de la plantación, el destino del fruto (mesa/almazara), las labores agronómicas dominantes, las pendientes sobre los que se instalan o el régimen del cultivo que se practica (secano/ regadío), el aspecto y funcionalidad de los olivares difieren notablemente. Una traducción de esta diversidad es la existencia de explotaciones muy contrastadas en términos de producción y rentabilidad económica (Sánchez y Gallego, 2011).

El olivar tiene, por otra parte, una inmensa capacidad para generar bienes patrimoniales. Desde luego, su potencial se deriva del carácter emblemático que el árbol ha adquirido a lo largo de la Historia debido a su longevidad, rusticidad y porte estético; y a las prestigiosas y variadas utilidades alimenticias, cosméticas y terapéuticas de sus productos (Anglés, 2009). Y, por descontado, tiene que ver también con la peculiar organización económica y social que ha permitido su creación, explotación y mantenimiento. Las diferentes manifestaciones culturales que se han ido generando, ya sean materiales o inmateriales, se perciben y reconocen como señas de identidad que trascienden sus propios valores de uso original, como ocurre con útiles y aperos de cultivo, inmuebles 
asociados al cultivo y la transformación del producto (cortijos y almazaras), rituales y actos festivos, conocimientos gastronómicos, etc.

En la actualidad, la lógica económica imperante impone una homogeneización abrumadora del paisaje agrario, la profunda alteración de sus bases naturales, la transformación de los sistemas de cultivo y la pérdida de ciertas manifestaciones culturales. El cultivo olivarero refleja en la actualidad un conflicto de naturaleza esencial: la lucha entre la tradición y el cambio, perceptible de forma inmediata en el valor central y dominante que ha ido adquiriendo la comercialización del aceite en la diversa y rica cultura del olivo, hasta llegar casi a monopolizarla. Se da la circunstancia, por otra parte, de que en pura lógica de mercado una gran parte de los olivares tradicionales (a menudo los de mayor interés paisajístico y patrimonial) presenta actualmente escasos o nulos márgenes de rentabilidad y, en todo caso, resulta muy dependiente de las ayudas de la Política Agrícola Común, todo ello sin olvidar que se basa en prácticas de manejo de los recursos naturales claramente insostenibles (Delgado Cabeza, 2014).

En este marco, además de tener mucho sentido el desarrollo de estrategias para la cualificación/diferenciación del aceite o para acaparar un mayor porcentaje de valor añadido por parte de los territorios productores, se profundiza también en el interés por recuperar los valores patrimoniales relacionados con el olivar, en tanto que elementos capaces de generar identidad pero también como recursos potenciales para promover la proyección turística de los territorios especializados en su cultivo. En este sentido, el papel de las administraciones públicas, en tanto que agentes de desarrollo territorial y potenciadores de la multifuncionalidad en el medio rural, resulta decisivo. En nuestro trabajo nos proponemos, después de profundizar en los aspectos que acabamos de esbozar, analizar el conjunto de iniciativas surgidas para cumplir con este propósito de recuperación y promoción del patrimonio como recurso para el desarrollo cultural y económico. Por razones que ahora daremos, vamos a utilizar como espacio geográfico de referencia la provincia de Jaén. En 2012, la superficie destinada al olivar superó las 584 mil ha, lo que supone que un $91 \%$ de las tierras cultivadas está ocupada ya por esta planta; de esta manera, Jaén concentra casi el $40 \%$ del olivar andaluz y algo más del $23 \%$ del total nacional ${ }^{3}$.

\section{LA EXPANSIÓN DEL OLIVAR POR TIERRAS DE JAÉN}

El cultivo olivarero está presente en la mayoría de regiones españolas, aunque es característico de los climas secos y, especialmente de las zonas más termófilas. En la provincia de Jaén encuentra unas condiciones edafoclimáticas excepcionales y así se explica que se alcancen los rendimientos medios de fruto más elevados del país. La concentración productiva es, por tanto, aún mayor que la superficial, como podemos comprobar en el gráfico $\mathrm{n}^{\circ} 1$, donde se toma como variable el olivar destinado a almazara, mayoritario en dicho territorio y se recogen datos de una campaña favorable desde el punto de vista meteorológico.

3 Ministerio de Agricultura, Alimentación y Medio Ambiente del Gobierno de España. Anuario de Estadística Agraria de 2013. http://www.magrama.gob.es (acceso de 20-09-2014). 


\section{Gráfico 1 \\ PRODUCCIÓN DE ACEITUNA (KG/HA) \\ DESTINADA A ALMAZARA EN 2009}

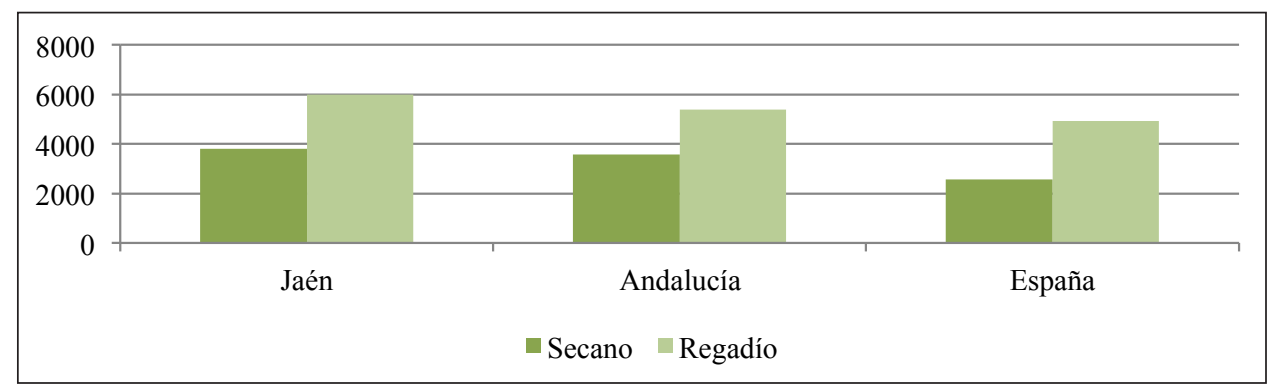

Fuente: Ministerio de Agricultura, Alimentación y Medio Ambiente del Gobierno de España. Anuario de Estadística Agraria de 2010.

La especialización productiva es más rotunda si tenemos en cuenta, por otra parte, el casi absoluto predominio de la variedad picual. Considerada de elevado rendimiento y con gran estabilidad de la grasa rendida, este predominio implica algunas dificultades logísticas derivadas de la madurez simultánea del fruto, algo que se tiene que sortear disponiendo de un extraordinario despliegue de medios para la recogida y una no menos importante red de almazaras. Por otra parte, la situación actual, que llega a registrar numerosos casos de monocultivo absoluto a escala municipal, es, contra lo que pueda pensarse, resultado de procesos relativamente recientes y se ha conformado a base de coyunturas muy favorables acaecidas cíclicamente. Como podemos ver en el gráfico $\mathrm{n}^{\circ} 2$, a mediados del siglo XVIII su presencia era muy modesta; a finales del XIX ya era ubicuo y ocupaba un tercio de las tierras cultivadas; para subir a dos tercios en la octava década del siglo XX y a más del $90 \%$ pocos años después.

\section{Gráfico 2}

\section{EVOLUCIÓN DE LA SUPERFICIE PLANTADA DE OLIVAR $(H A)$ EN LA PROVINCIA DE JAÉN (1752-2012)}

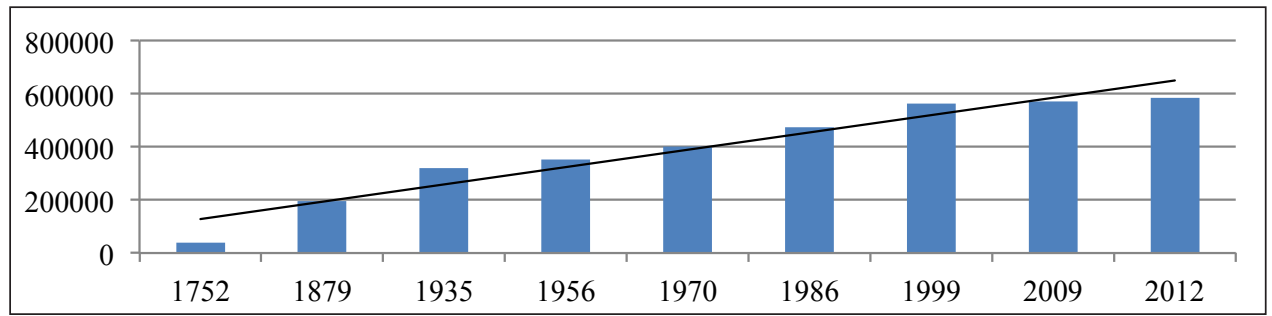

Fuentes: Garrido (2005); MAGRAMA (2010 y 2013); Sánchez Salazar (1989).

En todo caso, este lapso de tiempo ha llevado a la coexistencia actual de explotaciones olivareras surgidas en contextos pre-productivistas, productivistas, postproductivistas y 
neopreoductivistas, que responden en lo esencial a lo planteado de forma más genérica para el conjunto de la agricultura española (Silva Pérez, 2009). Hasta el siglo XIX, el olivar jiennense, como la mayoría del andaluz, formaba parte de un policultivo propio de una economía de subsistencia sin apenas excedentes. A mediados de ese siglo, de acuerdo con el estudio de las respuestas generales del Catastro del Marqués de la Ensenada, se alcanzaban las 39.000 $h a$, siendo éstas de secano y muy extensivas, ajenas desde luego a las tierras de primera calidad; era además inexistente en numerosos municipios, razón que avala la afirmación de que «el olivo tenía escasa importancia en el Reino de Jaén» (Sánchez Salazar, 1989, 89). Si la producción se veía limitada por la mala calidad de la tierra, los rendimientos grasos de la aceituna se veían lastrados por la tecnología, incapaz en aquellos momentos de extraer más del $17 \%$ del contenido graso del fruto. Esto, desde luego, no permite minusvalorar un cultivo del que se obtenían múltiples utilidades económicas: consumo humano directo, lubricación de maquinaria, elaboración de jabones, iluminación, calefacción, combustible, abono y complemento alimenticio del ganado (Infante Amate, 2012).

El siglo XIX conoce una importante expansión del olivar: en 1888 se estimó la superficie ocupada por esta planta en algo más de 193 mil ha (Dirección General, 1891). Esta fuente desglosa los usos del suelo de acuerdo al régimen del cultivo, diferenciando entre los secanos, regadíos constantes y eventuales. El recuento preciso de la superficie ocupada por el olivar no es fácil de dilucidar pues, de un lado, se recogen aquellos árboles que tenían plantación pura y regularmente distribuida; pero, de otro, aparecen los que formaban parte de parcelas con agricultura promiscua, fundamentalmente por la asociación de olivos con viñas y otros frutales (tabla 1).

\section{Tabla 1 \\ SIGNIFICACIÓN DEL OLIVAR RESPECTO AL RESTO DE LAS SUPERFICIES PRODUCTIVAS, PROVINCIA DE JAÉN 1879}

\begin{tabular}{lcccc}
\hline & $\begin{array}{c}\text { Regadío } \\
\text { constante }(h a)\end{array}$ & $\begin{array}{c}\text { Regadío } \\
\text { eventual }(h a)\end{array}$ & $\begin{array}{c}\text { Secano } \\
(h a)\end{array}$ & $\begin{array}{c}\text { Total } \\
(h a)\end{array}$ \\
\hline Superficie olivar puro (a) & 11.694 & 7.011 & 141.265 & 159.970 \\
Sup. viña, olivar y otros (b) & 2.013 & 318 & 33.071 & 35.402 \\
Total superficie olivar (a + b) & 13.707 & 7.329 & 174.336 & 195.372 \\
Superficie agrícola (c) & 29.225 & 9.812 & 518.000 & 557.037 \\
$($ a)/(c) \% & 40,01 & 71,45 & 27,27 & 28,72 \\
$($ a+b)/(c) \% & 46,90 & 74,69 & 33,66 & 35,07 \\
\hline
\end{tabular}

Fuente: Dirección General del Instituto Geográfico y Estadístico (1888).

Este avance decimonónico se realizó a costa de la ocupación de terrenos anteriormente destinados a cultivos anuales (proceso de sustitución), pero también a través de la profunda reconversión de usos que sucedió a la roturación de manchas de vegetación espontánea que hasta entonces se dedicaban a pastos y producciones forestales, es decir, como consecuencia de una ampliación de la frontera agrícola. Tales cambios tienen lugar en un contexto que supone la aparición de un mercado de la tierra, mediante la 
desvinculación de la propiedad señorial y la desamortización de bienes públicos. Estos últimos, mayoritariamente compuestos por predios pertenecientes al Estado y lo pueblos, ya fuera de naturaliza concejil o comunal, fueron objeto de repartos y ventas cuya intensidad y objetivos fueron cambiando a lo largo de la centuria. La propiedad señorial, por su parte, se fue enajenando voluntariamente y dio paso a la aparición de una burguesía agraria, muy beneficiada también con las facilidades que encontró para hacerse con los bienes desamortizados a partir de la segunda mitad del siglo. Eso sí, si estas tierras nuevas se fueron llenando de olivos fue porque los precios al alza del aceite y el incremento de la población así lo estimularon. De hecho, los molinos aceiteros estaban presentes en la mayoría de los municipios andaluces si se atiende a informaciones como las ofrecidas por el diccionario geográfico de Madoz. Es más, la consulta de esta obra permite identificar y datar la novedosa especialización de algunas zonas de la campiña jiennense ya durante la primera mitad del siglo. Pero el aceite fue también demandado para la exportación por su utilidad en el alumbrado público de algunas urbes europeas, hasta que fue drásticamente sustituido por el petróleo (Guzmán Álvarez, 2007).

En las primeras décadas del siglo XX y, en particular, desde 1913 a 1933, se asiste a uno de los hitos expansivos del olivar jiennense, en medio de la que ha sido calificada como «edad de oro del olivar» (Zambrana Pineda, 1987). La superficie cultivada, las cosechas y los precios del aceite no pararán de crecer y una de las claves para conseguir tales beneficios fue la mejora y sistematización de los cuidados de la planta ${ }^{4}$, como también lo fue el hecho de que numerosos propietarios, estimulados por los precios, se decidieran a gestionar directamente sus explotaciones para mejorar los resultados económicos de las mismas. Al tiempo, se asiste a una recuperación de los mercados internacionales, y no ya para destinar a ellos aceites de uso industrial sino para el consumo humano, algo que solo fue posible mejorando sensiblemente la calidad del producto, como sucedió con la satisfacción de las demandas de la industria conservera de pescado de Noruega (Hernández Armenteros, 2001). Cuando, a finales de los años 30, finaliza esta coyuntura favorable, el olivar jiennense ocupaba ya $320.000 \mathrm{ha}$.

La Guerra Civil y la dura posguerra significaron abandonos culturales y pérdida de mercados internacionales, de manera que se retrocedió en rendimientos y calidad. Es más, casi todas las propuestas de desarrollo rural, incluyendo el famoso Plan Jaén, compartían la idea de que era necesario paralizar la expansión del olivar por su incapacidad para generar empleos durante la mayor parte del año y que, en todo caso, los olivos no debían ser destinatarios de los recursos hídricos que se estaban movilizando a partir de la construcción de grandes embalses, pues se entendía más apropiado emplearlos en productos hortofrutícolas e industriales (Gallego Simón, 2014). Desde luego, este tipo de intenciones no llegaron a cumplirse. En 1956, con motivo de la publicación de la Reseña Estadística de la Provincia de Jaén (INE, 1956), más de la mitad de la superficie cultivada se encontraba dedicada al olivar (340.186 ha), si bien tan solo en la comarca de Sierra Morena adquiría tintes de monocultivo destacado y el olivar de regadío aún no había adquirido el protagonismo que después tendría.

4 A este particular, cabe destacar la labor de extensión agraria facilitada por la apertura de una Escuela de Olivicultura en la Granja Escuela Práctica de Agricultura, ubicada en Jaén (Garrido González, 2005). 
El fin del intervencionismo de la etapa autárquica abre otro período de la historia del olivar jiennense, dando paso a la denominada «crisis del olivar tradicional» (Naredo, 1983), motivada entre otras razones por la inundación del mercado interior con aceites de semillas, pero sobre todo por el incremento de los salarios en el campo, lo que significó una considerable pérdida de rentabilidad que incluso supuso el arranque de olivos en determinados lugares. La crisis se hizo palpable especialmente a partir de 1973 y de ello dan buena prueba los esfuerzos realizados por el Ministerio de Agricultura para averiguar y tratar de paliar la situación del sector. Así, en el III Plan de Desarrollo se incluyó un apartado consistente en la realización de un «Inventario y estudio técnico del olivar», que formó parte del «Programa de reconversión del olivar y otros cultivos problema». El diagnóstico dio comienzo en 1972 y, en el caso de la provincia de Jaén, los resultados fueron publicados tres años después (Ministerio de Agricultura, 1975). En este trabajo se recoge una cantidad de 434.999 ha distribuidas entre las ocho comarcas olivareras establecidas en dicho estudio. Del total mencionado, tan solo el 7,8\% se regaba, y las producciones medias del olivar adulto eran de $1.565 \mathrm{~kg} / \mathrm{ha}$ ( 1.332 en secano y 2.044 en regadío), si bien más del $50 \%$ de las producciones estaban por debajo de los $1.500 \mathrm{~kg} / \mathrm{ha}$.

Estas actuaciones tuvieron continuidad entre 1982 y 1988, con motivo de la puesta en marcha del «Plan de reestructuración del olivar mejorable y reconversión de comarcas olivareras deprimidas». En la doble orientación que este programa perseguía, las actuaciones encaminadas a la reconversión se efectuaron en 21.807 ha, mientras que el capítulo de reestructuración, (en la que la actuación preferida fue la instalación de regadío), afectó a 15.648 ha . En definitiva, la superficie total intervenida en la década y media en que fue posible acogerse a las ayudas procedentes del Ministerio fue más bien modesta, sobre todo teniendo en cuenta que a la finalización del último plan el olivar jiennense era casi un $25 \%$ más extenso que el existente en 1972. Aunque no se debe menospreciar el efecto de demostración que tuvieron los nuevos olivares intensivos (más densos, de un solo pie y regados), o el interés que adquirió la plantación de frutales como los cerezos entre las hileras de olivos, algo que todavía pervive en algunos municipios de Sierra Mágina (Torres) y la Sierra Sur (Castillo de Locubín), lo cierto es que la profunda reconversión productiva que se reclamó para el olivar provincial sólo se llevó a cabo de forma generalizada cuando empezaron a llegar los estímulos productivistas que la aplicación de la PAC iba a suponer a partir de 1986 (Sánchez y Gallego, 2011).

La clave que permite entender la fiebre olivarera desatada a partir de la adhesión de España al Mercado Común Europeo es la lógica productivista/proteccionista de la PAC entonces vigente. La Organización Común de Mercado de las grasas vegetales ${ }^{5}$, cuya primera versión fue aprobada en 1966, creó como instrumento básico la existencia de un precio de garantía al productor que siempre era superior al de los mercados mundiales, y puso en marcha sistemas de ayudas directas a la producción y el consumo, pero también establecía mecanismos de protección aduanera y restituciones a la exportación. Por si estas estrategias no fueran suficientes para asegurar las rentas de los productores, y para el caso de que se generaran excedentes, se podía recurrir igualmente a limitar la oferta mediante contratos de almacenamiento. El planteamiento, por tanto, era asegurar la venta de todo lo producido a precios remuneradores y era claro que eso se conseguía a la perfección (Jiménez Sánchez, 1997).

5 Reglamento $n^{\circ}$ 136/66 CEE del Consejo, de 22 de septiembre. 
Se define, por tanto, una etapa de auge productivista que tiene un perfecto correlato en el incremento de la superficie pero, sobre todo, en el incremento de las cosechas, gracias especialmente a la masiva penetración del regadío en este cultivo, hasta alcanzar las 270.000 ha que se estiman en la actualidad6 (MAGRAMA, 2013). De todas formas, los estímulos fueron reduciéndose durante años posteriores, en un contexto de reducción de los presupuestos comunitarios que inauguraron una etapa postproductivista y de progresiva desregulación (Araque, Gallego y Sánchez, 2002). Así, por ejemplo, las autoridades comunitarias eliminaron la concesión de ayudas a la producción para todas las plantaciones realizadas con posterioridad al 1 de mayo de 1998, si bien esto más que ralentizar la expansión superficial significó el desarrollo de una nueva revolución productivista y, con ello, la puesta a punto de modalidades aún más intensivas, capaces de competir en el mercado sin necesidad de ayudas públicas. En todo caso, el cambio más profundo fue el derivado de la supresión del precio de garantía, cuya función queda de manifiesto en períodos críticos como los actuales, en los que se denuncian situaciones de producción a pérdidas de acuerdo con los precios que obtienen los agricultores en origen. De todas formas, el modelo productivista intensivo quedó consolidado y, con ello, la estrategia económica basada en la competitividad por reducción de costes, con pocas y muy grandes almazaras que venden la mayor parte de su producción a granel.

\section{UN MONOCULTIVO CON DIFERENTES MANIFESTACIONES PAISAJÍSTI- CAS Y ECONÓMICAS}

En el seno del monocultivo, de aspecto aparentemente uniforme, podemos diferenciar explotaciones muy dispares de acuerdo a la gestión de los recursos naturales o de sus efectos sociales y económicos, con su correspondiente diversidad paisajística (véanse fotografías 1 a 4). Sintéticamente, cabe establecer al menos dos grandes categorías. De una parte, el olivar tradicional, en el que se encuentran entre 80 y 120 plantas/ha, de una antigüedad superior a 25 años, en régimen de secano y con rendimientos bajos, localizados sobre todo en las zonas de sierra. Por otra parte, los olivares de alta densidad, en el que se diferencian los olivares intensivos (200-600 plantas/ha) y superintensivos (1.000-2.000 plantas/ha). Estos son olivares regados, muy mecanizados, de elevados rendimientos y localización exclusiva en suelos con pendientes suaves de vega y campiña (Sánchez, Gallego y Araque, 2011). En el gráfico 3 se presenta la distribución de los olivares en relación a criterios como la pendiente, la densidad de la plantación, el régimen de cultivo. En ese sentido hay que destacar que la más representada, tanto en extensión como en número de explotaciones (se trata por tanto de un tipo claramente dominado por la pequeña propiedad) es la correspondiente a los olivares tradicionales difícilmente mecanizables (OTDM), a la que siguen los olivares tradicionales mecanizables (pendiente inferior a 15\%) en secano y regadío (OTMS, OTMR). Por su parte, los olivares de alta densidad de plantación (más de 200 olivos por hectárea) en secano y en regadío (OISyR) son prácticamente testimoniales.

6 Anuario de Estadística Agraria de 2013 (acceso de 04-12-2014).

http://www.magrama.gob.es/es/estadistica/temas/publicaciones/anuario-de-estadistica/ 


\section{Gráfico 3}

GRANDES TIPOLOGÍAS OLIVARERAS DE ACUERDO A CRITERIOS DE PRODUCTIVIDAD Y RENTABILIDAD ECONÓMICA

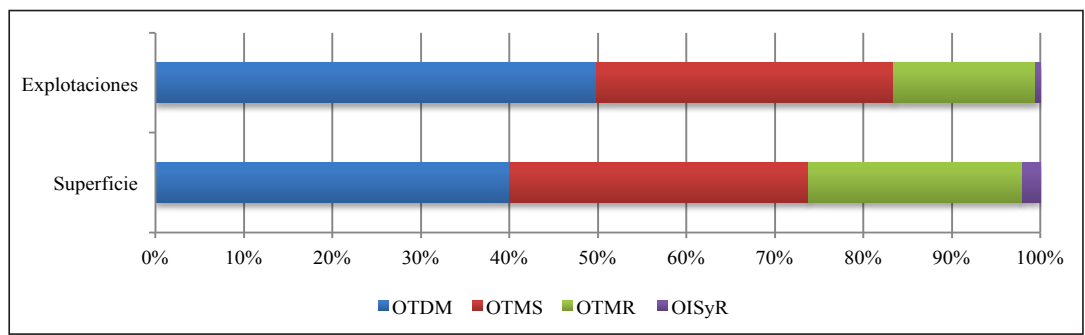

Fuente: Consejo Económico y Social de la Provincia de Jaén (2011).

Foto 1

OLIVAR TRADICIONAL ATERRAZADO EN PELAGAJAR

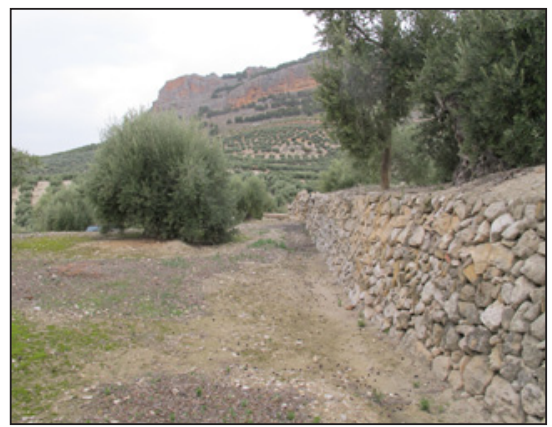

Foto 3

OLIVAR MARGINAL EN EL CERRO DE LA VICARÍA (JAÉN)

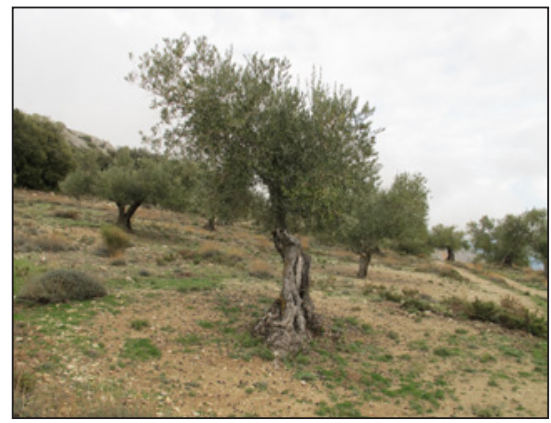

Fotografías de los autores.
Foto 2

OLIVAR SUPERINTENSIVO EN EL VALLE DEL GUADALBULLÓN (JAÉN)

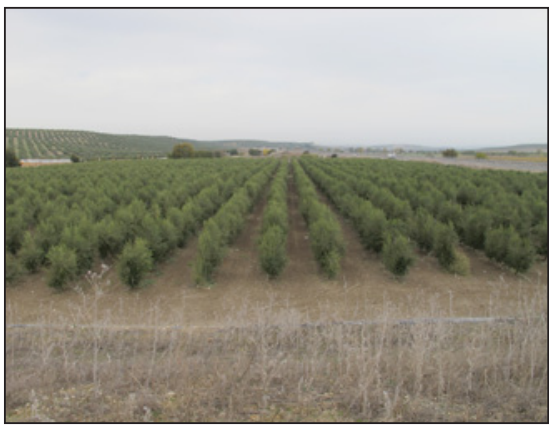

Foto 4

OLIVARES EN EL CONTACTO DE LA LOMA DE ÚBEDA Y EL VALLE DEL GUADALIMAR

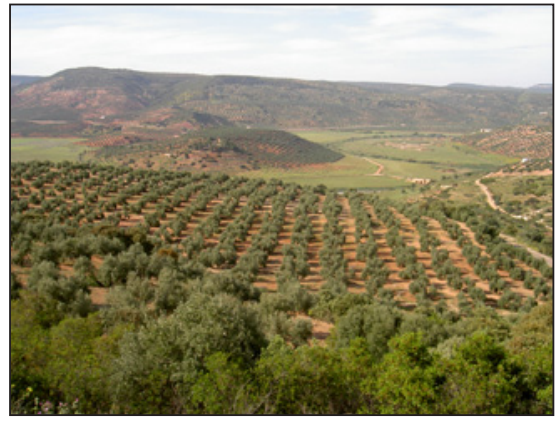


Algunos datos nos pueden ilustrar sobre esta heterogeneidad a que nos estamos refiriendo. Por ejemplo, respecto a la propiedad de la tierra, en 2005 se contabilizaron 140.653 explotaciones para un total de 562.948 ha, es decir, una media de 4 ha por explotación 7 . Si consideramos la distribución del tamaño de estas explotaciones (gráfico 3), se comprueba que más del $82 \%$ de estas se encuentran por debajo de 5 ha, lo que supone casi un $40 \%$ de la superficie total. En cambio, las mayores de 50 ha representan sólo el $0,76 \%$ y acaparan el 13,29\% del cultivo. Junto al minifundismo y la atomización parcelaria, otro elemento que nos permite acercarnos a la diversidad a la que antes nos hemos referido es la distribución de la superficie cultivada según la pendiente. Aunque en esta ocasión las cifras medias esconden una gran dispersión típica, derivada de la condición campiñesa, alomada, montañosa o mixta de cada municipio, no ocultan la existencia de una superficie en situaciones de dificultad objetiva. De hecho, sólo una cuarta parte del total se encuentra por debajo del umbral del $10 \%$ de inclinación.

\section{Gráfico 4}

\section{DISTRIBUCIÓN (\%) DE LAS EXPLOTACIONES OLIVARERAS SEGÚN SUPERFICIE Y NÚMERO EN 2005}

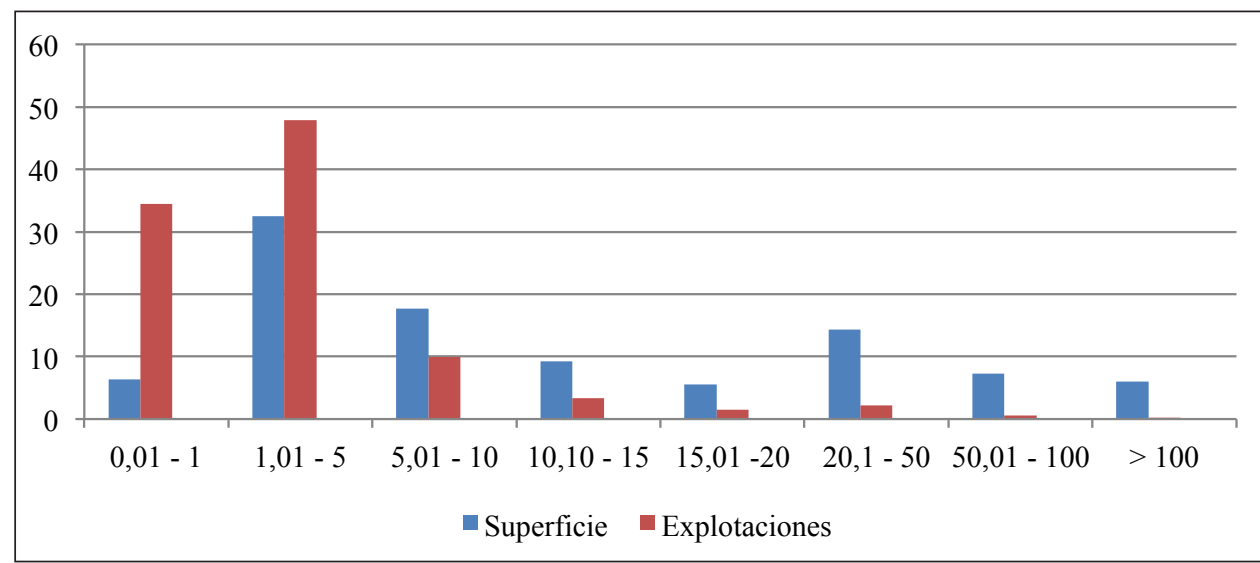

Fuente: Consejería de Agricultura y Pesca de la Junta de Andalucía. Delegación Provincial de Jaén.

El último elemento que vamos a utilizar para insistir en la idea de la convivencia de olivares muy diferentes es el de los rendimientos en la producción de aceituna. La media provincial para el período 1990-2005 fue de $3.568 \mathrm{~kg} / \mathrm{ha}$ en secano y $4.221 \mathrm{~kg} / \mathrm{ha}$ en regadío. Está claro, por tanto, que el salto de producción es espectacular comparando estas cifras con las que hemos dado para otros momentos históricos. Ahora bien, la distribución de estas medias es bastante desigual, como puede verse en el gráfico 5. Así, el 18,54\% presenta una media superior a los $6.000 \mathrm{~kg} / \mathrm{ha}$, mientras que el $60,01 \%$ se sitúa por debajo de los $4.000 \mathrm{~kg} / \mathrm{ha}$.

7 Aunque hay datos posteriores más actualizados (Censo Agrario de 2009), nosotros hemos seguido aquí la información facilitada por la Delegación Provincial de Agricultura, que desglosa la situación a nivel municipal. 


\section{Gráfico 5 \\ DISTRIBUCIÓN (\%) DE LOS RENDIMIENTOS MEDIOS DE ACEITUNA (KG/HA) DEL PERÍODO 1990-2005}

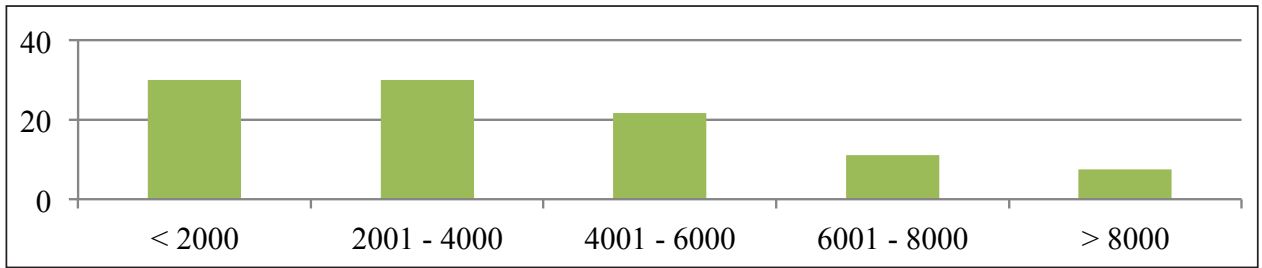

Fuente: Consejería de Agricultura y Pesca de la Junta de Andalucía. Delegación Provincial de Jaén.

\section{LA DIMENSIÓN PATRIMONIAL DE LA ACTIVIDAD AGRARIA}

Los territorios rurales, anteriormente percibidos como atrasados o poco civilizados, vienen siendo contemplados en su dimensión patrimonial sólo durante las últimas décadas. El reconocimiento pasa por considerar a la actividad agraria productiva como generadora de manifestaciones de interés arquitectónico, utilitario, paisajístico, histórico, etnológico, etc. Probablemente, el concepto de paisaje sea el más elaborado desde el punto de vista teórico y al que más se ha recurrido para la aprobación de normativa cuando de dar sustento a esta nueva visión se refiere. En concreto, la figura de «paisaje cultural» es la que ha tenido un mayor desarrollo legal, refiriéndose a una serie de bienes naturales y culturales que configuran una unidad territorial y que es susceptible de una gestión ordenada, cuestión que ha llevado a hitos como su reconocimiento por parte de la UNESCO a ser incluido en la lista del Patrimonio Mundial (Silva Pérez, 2008). Sobre este aspecto, no obstante, volveremos a reparar al final de este trabajo.

Siguiendo un camino similar al experimentado por el patrimonio urbano, en el caso de las actividades agrarias lo primero que ha alcanzado la consideración de patrimonializable son las manifestaciones relacionadas con la arquitectura de las clases dirigentes, al parecer más evidentes en sus valores históricos y artísticos para el esquema cultural dominante (es el caso de las haciendas y los cortijos andaluces), así como los grandes complejos productivos relacionados con el patrimonio industrial (molinos, lagares, almazaras); a los que se han unido también determinados paisajes de especial valor ambiental y estético, o bienes materiales e inmateriales de valor etnológico, base a menudo del contenido de museos agrícolas, o de artes y costumbres populares; así como fiestas o gastronomía singular (Amaya Corchuelo, 2010).

Así, a pesar de que el avance teórico de los últimos años se dirige a la consideración conjunta de los valores históricos y naturales de los espacios agrarios, ampliando la tipología de bienes a proteger en una concepción globalizadora que se plasma en el territorio; a efectos prácticos lo que ha dominado es el reconocimiento y protección de manifestaciones individualizadas del patrimonio agrario, como objetos de valor intrínseco, pero aislados del componente que sustenta su propia esencia, es decir, de la actividad agraria que los genera. Los esfuerzos de protección a nivel internacional y nacional se han centrado en los valores naturales antes que en los culturales, con la consiguiente dificultad 
para el reconocimiento patrimonial de la agricultura, solo considerada (indirectamente por lo general) en figuras como las de Paisajes e Itinerarios Culturales de la Convención del Patrimonio Mundial de la UNESCO y, en el caso de España, a las de Sitio Histórico y Lugar de Interés Etnológico. Así, la mayor parte de las Reservas de la Biosfera o de los Paisajes e Itinerarios Culturales incluidos en la Lista del Patrimonio Mundial, apenas tienen relación con la agricultura y se centran en el reconocimiento y la protección de los valores naturales de esos territorios (Castillo y Martínez, 2014). La declaración y gestión de los Parques Naturales de Andalucía es un ejemplo de esta tendencia.

En definitiva, los valores patrimoniales de la actividad agraria han sido tímidamente reconocidos y el peligro de destrucción y alteración del mismo es muy elevado en numerosos espacios y bienes agrarios históricos o tradicionales, lo que convierte en urgente la necesidad de crear un sistema de protección basado en su condición cultural, que permita articular e interrelacionar todas las dimensiones patrimoniales que concurren en los bienes agrarios. Un intento de impulsar estas acciones es el planteamiento formulado en la Carta de Baeza sobre Patrimonio Agrario, del que se dice que «está conformado por el conjunto de bienes naturales y culturales, materiales e inmateriales, generados o aprovechados por la actividad agraria a lo largo de la historia» (Carta de Baeza, 2013, 32).

\section{EL OLIVAR COMO PATRIMONIO CULTURAL}

Lo que resulta indudable es que la persistencia y destacada presencia del olivar ha ido generando manifestaciones culturales de todo tipo, paulatinamente asumidas como señas de identidad que van mucho más allá de sus propios valores originales: útiles y aperos, técnicas de recolección y molturación, inmuebles asociados a la labranza o la transformación del producto (cortijos, almazaras); construcciones inmateriales nacidas de la actividad agrícola y sus frutos: rituales y actos festivos, conocimientos agronómicos, gastronomía; e incluso el patrimonio natural y genético: vegetación y fauna asociada, desarrollo de variedades locales, formas de manejo del suelo, etc. Desde luego, la recolección era (y en parte sigue siendo) el momento de mayor actividad y contacto humano, en el que se reproducían los parámetros de división social y sexual del trabajo (hoy trastocados por la irrupción del nuevo jornalero inmigrante y la desaparición del papel de la mujer), el modelo de actividad agrícola tradicional (muy alterado en la actualidad por la mecanización), y de la cultura y los valores de la sociedad rural, representados en sus costumbres y el folklore (Anta, 2005). En suma, el olivar en Jaén se ha configurado a lo largo de los siglos como un universo económico y social capaz de construir un espacio cultural definido, de ahí que el aceite, el olivar y los aceituneros se hayan convertido en símbolos de la provincia ${ }^{8}$.

Estos rasgos culturales, lógicamente, están hoy en extinción ante los cambios radicales introducidos por la total orientación capitalista que presenta la olivicultura. Las manifestaciones de estas transformaciones se han visualizado en la abrumadora homogeneización del paisaje agrario, la profunda alteración del medio natural, la transformación de los procesos de cultivo, la pérdida del carácter familiar y la progresiva desaparición de ciertas

8 Cabe señalar, al respecto, la reciente adopción del poema «Aceituneros» (Miguel Hernández, 1937) como himno oficial de la provincia. http://www.dipujaen.es/conoce-diputacion (acceso de 04-12-2014). 
manifestaciones culturales. En el momento actual asistimos a un conflicto económico, social y cultural entre tradición y modernidad, cambio y costumbre (Palacios, 2005), que plantea diferentes retos y peligros a tener en cuenta desde la perspectiva patrimonial. Uno de los aspectos más visibles de esas transformaciones es la transferencia del valor simbólico que se ha producido desde el árbol al aceite, convertido en elemento central de atención con motivo de la mercantilización absoluta (Anta, 2002; Palacios, 2002; Cobo de Guzmán, 2005). En la actualidad, el aceite es el producto que representa el mercado, a cuyos intereses se adapta con nuevas formas de diseñar el cultivo o mecanizaciones para una recolección más productiva.

A pesar de ello, es evidente que el aceite es el valor fundamental que da origen al complejo andamiaje cultural del mundo del olivar. Todo lo relacionado con la utilización tradicional de esta grasa, tanto en la gastronomía como en otros campos (industria, cosmética, etc.), forma parte de un corpus cultural de dimensión histórica, ligado al mundo mediterráneo, que es el que le otorga su valor patrimonial fundamental. A la famosa tríada básica que ha nutrido a los habitantes de este entorno geográfico de pan, vino y aceite, hay que unir legumbres, hortalizas y verduras, frutas diversas y los productos que aportó América. Gracias a todo ello se conformó uno de los modelos alimentarios más equilibrados y saludables del planeta. El consumo de la aceituna verde en sus múltiples variedades (aliñada, machacada o rajada, sean de la variedad gordal o de cornezuelo), el aceite para freír y como sustento de los guisos propios de estos lares, incluso como conservante de «la matanza» con aportaciones tan estimadas como el «lomo de orza». Su presencia histórica lo hace inseparable del modo de alimentarse y de los sabores y olores que forman parte de la identidad cultural de las gentes de estas tierras (Amaya Corchuelo, 2010).

Sin embargo, hasta hace poco, los múltiples bienes patrimoniales asociados al olivar rara vez se han integrado en actuaciones culturales o expositivas específicas de este cultivo. En consonancia con las tendencias que han dominado en el terreno del patrimonio, los bienes relacionados con el olivar más tempranamente reconocidos han sido los arquitectónicos. En algunos casos, las haciendas y cortijos que, aunque en general no hayan tenido su origen en el cultivo olivarero sí han terminado por quedar asimilados al mismo. A pesar de la enorme diversidad de este tipo de construcciones, la inicial reivindicación y recuperación del cortijo se vincula más a su condición de vivienda señorial que a su vertiente productiva; y con los latifundios más que con la pequeña y mediana propiedad de tipo familiar. En buena parte de los casos, su valoración ha venido de la mano de sus características artísticas y arquitectónicas y de su reutilización en el campo del turismo y la hostelería, esto es, como objetos de valor en sí mismos, sin una mayor vinculación territorial, cultural o agrícola. En algunas ocasiones esos cortijos se dotaron de molinos de aceite propios (almazaras) que facilitaran el ciclo completo de la producción.

Aunque en la mayor parte de los casos el molino o almazara es una construcción industrial que ha sufrido muy pocos cambios hasta bien entrado el siglo XX, su condición de establecimiento fundamentalmente urbano, casi artesanal y de producción muy limitada ha ido modificándose profunda y rápidamente. Un número muy elevado desaparecieron y otros se reconvirtieron en modernas plantas de fabricación de aceite. Su existencia corre, pues, pareja a la extracción del aceite y ha sufrido la evolución histórica propia de los cambios generados en la tecnología, el volumen de producción y las necesidades 
del mercado. La documentación histórica y estudios realizados nos permiten conocer diversos tipos de molinos ya desaparecidos (Rojas Sola y García Hornos, 2007). A pesar de que se han podido conservar algunos ejemplares de valores históricos sobresalientes, unos en condiciones muy precarias y otros reconvertidos en monumentos, museos o parte integrante de ellos, el reconocimiento a sus valores históricos y culturales ha sido muy escaso y su protección ha dependido, en gran medida, de iniciativas privadas movidas, fundamentalmente, por su utilidad como producto turístico.

El valor otorgado a la arquitectura del olivar, cuando ha existido, lo ha sido de forma descontextualizada, individualizada, sin incorporar el complejo territorial y cultural del que forma parte, como un elemento singular del patrimonio arquitectónico o industrial. Sin embargo, sus potencialidades culturales son enormes. Además, con la democratización del concepto de patrimonio se ha ido extendiendo el interés por incorporar otros bienes como las casas de labranza, apriscos y construcciones adscritas a la función productiva, arquitectura popular vernácula, etc., aunque el grado de concienciación sobre la posible protección de estos bienes (ya casi inexistentes) es muy bajo.

En el caso de los útiles, aperos y herramientas relacionados con el proceso de cultivo y recolección, las vertiginosas modificaciones producidas en pocos años han llevado al arrinconamiento y casi el olvido a la mayoría de los bienes que componían ese mundo material: espuertas, varas para derribar la aceituna, capachas, cribas, mantones, muelas de molino, distintos tipos de prensas, capachos, etc. En el mejor de los casos han entrado a formar parte de exposiciones etnográficas o de museos de artes y costumbres populares, que fijaron parte de su atención en los útiles y herramientas, mobiliario y enseres relacionados con las actividades agrícolas y ganaderas desaparecidas o en desuso (Ortega Ruiz, 2010). En consonancia con la visión peyorativa del mundo agrario y las tendencias dominantes del elitista mundo cultural, durante mucho tiempo esos bienes materiales han venido siendo considerados como artesanía popular no susceptible de entrar en el noble y, a menudo, clasista mundo de lo patrimonializable.

Por otro lado, hay que resaltar que en los últimos años se ha producido un importante aumento del interés por el concepto de paisaje, paralelamente a la toma en consideración del importante papel que tiene la agricultura en el mantenimiento de la biodiversidad y el patrimonio natural, lo que ha facilitado su valoración y reconocimiento institucional a nivel internacional. En el caso español, tanto dehesas como olivares han venido siendo objeto de un número creciente de investigaciones y acciones desde este punto de vista. Sin embargo, la relación paisaje-patrimonio aún no termina de ser articulada satisfactoriamente como demuestra que las referencias al paisaje por parte de las instituciones de patrimonio sean muy recientes y las figuras de protección escasas e imprecisas (Silva, 2009). Menos planteado aún (ni por supuesto resuelto) está ese problema en relación a los paisajes agrarios, ya que hablamos de construcciones culturales y no de espacios naturales.

Precisamente la imagen del paisaje del llamado «mar de olivos» es, al menos en Jaén, una de sus identidades más definida. Un paisaje fruto de la acción humana, consecuencia de una actividad productiva que ha evolucionado notablemente con el tiempo. Como hemos dejado apuntado más arriba, el paisaje histórico del olivar en la provincia de Jaén dista mucho del existente en la actualidad, fruto del monocultivo extensivo y las nuevas incorporaciones intensivas. Pero nuestro interés no está en la consideración ecológica, 
natural o estética del paisaje, sino en su patrimonialización, hasta ahora sólo vagamente resuelta a partir de la definición de Paisajes Naturales (Castillo y Martínez, 2014).

Desde la perspectiva del Patrimonio Agrario el paisaje necesita de la confluencia de ciertos elementos y valores (que ya hemos apuntado en líneas precedentes) para convertirlo en patrimonializable $y$, por tanto, en objeto de protección para su permanencia como manifestación de una creación cultural. Los valores sociales y culturales del olivar (entre los que también está el paisaje), esos que consideramos patrimonializables, se han generado por y van unidos a un tipo concreto de cultivo tradicional, a unas plantaciones, a unas relaciones sociales y de producción, a un diálogo entre el ser humano, el medio y el territorio, que no son extensibles a todo el paisaje olivarero de la actualidad, tanto por consideraciones de tipo ecológico como por otras de tipo económico y cultural. La mecanización, la industrialización y la introducción de extensas áreas de cultivo de olivar intensivo y superintensivo han provocado modificaciones y alteraciones en el medio natural y en las relaciones sociales que han trastocado buena parte de lo que podíamos llamar la cultura del olivar, esa que ha venido conformándose a lo largo de los siglos. La existencia de un enorme peligro de destrucción o alteración irreversible de los espacios y bienes agrarios históricos o tradicionales por la expansión de sistemas productivistas e industrializados, por la desagrarización del mundo rural o por la pérdida de saberes y conocimientos tradicionales (Carta de Baeza, 2013), se hace bastante evidente en el caso del olivar.

No es fácil, pues, hacer un diagnóstico, desde la perspectiva del Patrimonio Agrario, de todo el paisaje del olivar como parte de un patrimonio cultural. Porque es precisamente el olivar tradicional, ese olivar que ha generado las manifestaciones culturales que lo definen, el que en la actualidad se encuentra en franco retroceso y en peligro de desaparición a causa de las modificaciones en el cultivo, la producción y el mercado. Un olivar tradicional que debe ser protegido no como un jardín, no como un paisaje fósil, ni como un simple producto turístico, sino como un medio de vida para miles de agricultores, que ha generado y genera un patrimonio cultural de enorme valor. Y eso necesita de compromisos a todos los niveles.

\section{INICIATIVAS DE PUESTA EN VALOR DEL PATRIMONIO DEL OLIVAR}

Hasta hace bien poco, el mundo agrario en general y el del olivar en particular han tenido una escasa valoración (por no decir nula) por parte del mundo de la cultura y del patrimonio, incluso en una provincia como la de Jaén que gira en torno a él y que, a pesar de la evolución socioeconómica de los últimos tiempos, sigue manteniendo su carácter rural y agrario. Y no digamos ya de la valoración del agricultor, del aceitunero, de los pequeños propietarios de explotaciones de tipo familiar, y de los jornaleros y jornaleras que se ganaban (y ganan) su escaso salario con enorme fatiga y esfuerzo.

Es de destacar que lo relacionado con los valores culturales históricos y tradicionales del olivar y la reivindicación de su vida cotidiana, está más representado en museos de vocación etnográfica que en los proyectos expositivos actuales, en los que el valor central se otorga al aceite como producto estrella y a su proyección comercial, a la empresa en detrimento del agricultor, olvidando a veces la dimensión humana y cultural. El conoci- 
miento que pueden transmitir personas que aún acumulan importantes saberes de la vida cotidiana del mundo del olivar es, en este aspecto, fundamental para mantener, recuperar, proteger y transferir todo ese capital cultural.

Con todo, no faltan ejemplos (aunque de valor muy desigual desde la perspectiva cultural y patrimonial) que tratan de paliar estas carencias. Es el caso del Museo de la Cultura del Olivo de la Hacienda La Laguna (Baeza), ubicado en una antigua gran explotación olivarera dotada de una almazara del siglo XIX de gran valor histórico y arquitectónico, que, desde nuestro punto de vista, se acerca bastante al concepto de representación de la cultura tradicional del olivar'.

Bajo otros planteamientos, se han creado el Centro de Interpretación del Olivar Ecológico en la población de Génave, localidad pionera en la producción de aceite ecológico situada en la primera comarca que contó con una Denominación de Origen Protegida (Sierra de Segura); o el Centro de Interpretación del Olivar y el Aceite de Oliva de La Loma $^{10}$, una instalación emplazada en el centro de la ciudad de Úbeda sobre un edificio histórico y que se concibe con un propósito múltiple: espacio museístico, de formación, ocio y expansión de la cultura del aceite, aspirando a convertirse también en un recurso turístico más para las personas que visitan las ciudades Patrimonio Mundial de la Humanidad de Úbeda y Baeza, reconocidas por su arquitectura renacentista.

El proceso de apertura de este tipo de centros no puede darse ni mucho menos por cerrado. Al proyecto anunciado hace unos años de crear una «almazara abierta» en la ciudad de Jaén (que aspira a convertirse en la «capital mundial del aceite»), hay que añadir otros como el de la creación de un Centro de Interpretación del Aceite de Oliva en las instalaciones de la Sociedad Cooperativa Andaluza Aceites de Cazorla, contemplado como un recurso más para dinamizar el sector turístico y cultural de la comarca de la Sierra de Cazorla, y que girará en torno a una almazara antigua para que se reconozca el valor de la producción artesanal de extracción del aceite que fue común hasta hace unas décadas ${ }^{11}$.

Con un propósito similar, en la comarca Sierra Sur de Jaén diferentes empresas de producción oleícola han acordado igualmente la puesta en marcha del proyecto Red de Almazaras Turísticas, concebido como centros interpretativos del aceite de oliva. La idea consiste en desarrollar un aspecto particular en cada una de las 10 entidades asociadas, con el propósito de crear un circuito de potencialidad turística, didáctica y dinamización de este territorio rural ${ }^{12}$.

Por su parte, el Museo Activo del Aceite de Oliva y la Sostenibilidad Terra Oleum, ubicado en el parque empresarial Geolit (Parque Científico-Tecnológico del Aceite y del Olivar) en Mengíbar, se define como un espacio de divulgación multidisciplinar (científica, tecnológica, socioeconómica y ambiental) que está dirigido a amplios sectores de la población. Se trata del espacio de mayor extensión y equipamiento de los que hasta ahora hemos descrito, pues el propósito es que se convierta en un espacio de referencia nacional para estas temáticas ${ }^{13}$.

\footnotetext{
9 http://www.oleotourjaen.es (acceso 5-12-2014).

10 http://centrodeolivaryaceitelaloma.com (acceso 5-12-2014).

11 http://aceitescazorla.com (acceso 5-12-2014).

12 http://www.redalmazarassierrasurjaen.es (acceso 5-12-2014).

13 http://www.terraoleum.es (acceso 5-12-2014).
} 
De unos años a esta parte, el conjunto de recursos de que dispone el territorio olivarero en Jaén, está siendo empleado también como base para promover la multifuncionalidad por parte de las instituciones públicas. En este sentido, cabe destacar el papel que están jugando la Junta de Andalucía y la Diputación Provincial de Jaén. Desde nuestro punto de vista, el denominador común y la llave que está permitiendo abrir la transformación de la realidad actual es la adquisición de una nueva cultura de la calidad del aceite (sobre todo con la proliferación de los denominados aceites de alta gama, los mejores entre los que adquieren la condición de extra virgen), que son el mejor reclamo para despertar el interés por conocer la riqueza y complejidad de los procesos, territorios y paisajes que están detrás de su producción, al igual que ha ocurrido anteriormente con la cultura de viñedo y el vino.

$\mathrm{Y}$ es que, en un panorama desolador para los olivares tradicionales menos productivos, se está produciendo un importante cambio de mentalidades respecto a la estrategia a seguir. Si bien todavía está dominada por la búsqueda de la mayor cantidad posible de producto, buscando el factor de competitividad en la reducción de costes; un buen número de empresas apuesta por la obtención de un aceite diferenciado, a menudo premiado en certámenes nacionales e internacionales y que el mercado puede reconocer como garantía de mejores parámetros organolépticos y químicos para la alimentación y la salud. Este proceso lleva a un cuidado extremo en el cultivo y la transformación de la aceituna, pero también al incremento de los porcentajes de producto que sale embotellado en origen, así como el desarrollo de estrategias propias de comercialización e internacionalización (Moral, Sánchez et al., 2014). Un hito destacado es, en este sentido, la importante acumulación de premios conseguidos de un tiempo a esta parte en certámenes nacionales e internacionales.

Especial importancia adquiere, en este contexto, la aprobación de la Ley del Olivar de Andalucía (2011). La finalidad de la misma ${ }^{14}$ es múltiple y persigue desde la eficiencia productiva, hasta el impulso de la investigación, el uso eficiente de los recursos o la promoción del consumo; e incluye también el propósito de «conservar y valorizar el paisaje y el patrimonio histórico y cultural del olivar y sus productos». Todo ello tiene que concretarse en la aprobación y dotación presupuestaria (asociada a los fondos de desarrollo rural) del Plan Director del Olivar Andaluz, documento que aún no ha visto la luz pero del que se conoce ya un borrador (junio 2014) donde se recogen las estrategias para la consecución de los fines previstos en la Ley.

Una buena forma de enfocar este propósito puede ser el propuesto en la Carta de Baeza sobre Patrimonio Agrario (2013), en la que se afirma que el ámbito de formalización de este patrimonio debe ser el territorial, de forma que su protección pasa por la selección y declaración de las zonas que lo merezcan bajo alguna de las tipologías de bien de conjunto previstas en la legislación actual (paisaje cultural, zona patrimonial, sitio histórico) o, incluso mejor, a través de una figura específica para reconocer la singularidad del patrimonio agrario, como pudiera ser la de Lugar de Interés Agrario.

14 http://www.boe.es/boe/dias/2011/11/07/pdfs/BOE-A-2011-17494.pdf (acceso 04-12-2014). 
Otro paso importante en la promoción de los territorios olivareros, en este caso bajo un planteamiento estrictamente turístico, es la creación de la Agrupación Empresarial Innovadora Paisajes del Olivo, promovida por la Secretaría de Estado de Turismo. Esta agrupación se define como «la combinación, en un espacio geográfico o sector concreto de empresas, centros de formación y unidades de investigación públicos y privados, involucrados en procesos de intercambio colaborativo, dirigidos a obtener ventajas y/o beneficios derivados de la ejecución de proyectos conjuntos de carácter innovador», y persigue como objetivo la consolidación de los paisajes del olivo como producto turístico sostenible. En este encuentro entre empresas, entidades tecnológicas y del conocimiento y administraciones se espera generar el caldo de cultivo apropiado para convertir al olivar en un destino turístico ${ }^{15}$.

Por el momento, el ejemplo más destacado de estrategia turística ligada al olivar es la protagonizada por la Diputación Provincial de Jaén. Dentro de su papel de agente de desarrollo territorial, y especialmente en la promoción del turismo (López Palomeque y Font Urgell, 2014), esta institución cuenta con numerosas experiencias previas, si bien ha llegado a su actuación más ambiciosa con el denominado Proyecto Oleotur Jaén (http://www.oleturjaen.es). Se trata de difundir los múltiples recursos que esta provincia tiene en relación con el aceite y el olivar, como por lo demás se está intentando en otros muchos lugres del país (Troitiño-Torralba, 2014); para permitir al visitante conocer el proceso de producción del aceite en las almazaras, participar en la fase de recogida del fruto durante la campaña, contemplar un paisaje que se pretende original y único en el mundo, degustar gastronomía basada en el empleo del aceite, alojarse en un cortijo u otros edificios singulares, recibir masajes con aceite, adquirir productos derivados del olivo o aprender a catar las características de los diferentes tipos de caldos.

Se trata, en definitiva, de presentar la oportunidad de disfrutar de experiencias novedosas, una opción de diferenciación turística en un mercado saturado y hasta hace poco dominado abrumadoramente por las fórmulas de sol y playa; y que también se puede complementar con el disfrute de la oferta relacionada con el patrimonio monumental y natural cercano, donde destacan las ciudades Patrimonio Mundial de la Humanidad de Úbeda y Baeza y la existencia de diferentes espacios naturales protegidos con abundante infraestructura turística y de uso público. De todos los recursos ofertados, que se agrupan en siete categorías diferentes (experiencias, almazaras, gastronomía, catas, museos, cortijos y paisajes), resulta especialmente interesante el último de ellos, que se nutre de elementos singulares (olivos centenarios), miradores para contemplar las grandes manchas de olivar y una ruta que permite conocer diferentes aspectos del cultivo y su aprovechamiento. Nos referimos a la Vía Verde del Aceite, surgida de la transformación de una antigua infraestructura de ferrocarril que se abandonó en los años ochenta del siglo pasado y que hoy se destina a la práctica del cicloturismo, el senderismo y otros deportes en contacto con la naturaleza. La ruta se extiende por $55 \mathrm{~km}$ y permite contemplar también atractivos patrimoniales como cinco estaciones del antiguo ferrocarril, túneles y viaductos metálicos de este trazado reconvertido con fines culturales y turísticos.

15 http://www.paisajesdelolivo.org (acceso 04-12-2104). 


\section{REFLEXIÓN FINAL. UNA APUESTA POR LA DINAMIZACIÓN DEL PATRI- MONIO DEL OLIVAR}

En la línea de trabajo que vienen desarrollando las administraciones públicas, la propuesta de revalorización del patrimonio cultural y de acondicionamiento turístico del olivar pasa ahora por el desarrollo de un proyecto integrador y aún más ambicioso que los descritos. En ese sentido, tal y como ha ocurrido con otra clase de bienes patrimoniales agrarios, y una vez más siguiendo los pasos del viñedo y el vino ${ }^{16}$, esta nueva fase va a estar marcada por el comienzo de los trabajos de redacción de un expediente que la Diputación Provincial de Jaén pretende realizar para conseguir que el olivar andaluz sea incluido en la lista del Patrimonio Mundial de la UNESCO, en la categoría de paisaje cultural. Se trata de liderar una iniciativa en la que se quiere implicar al resto de provincias andaluzas donde este cultivo tiene gran significación y no es la primera vez que el tema se plantea, pues ya en 2008 se realizó una declaración institucional en esa dirección, sin que llegara a concretarse en ningún sentido ${ }^{17}$.

Está claro que esta aspiración, de culminarse, sería un activo de desarrollo territorial. La oportunidad para la declaración, por el momento, se basa en la relativa escasa representación que los paisajes culturales (incluidos los agrarios) tienen en este listado mundial; lo que también ocurre en el caso de España (Fernández y Silva, 2015). En ese mismo sentido, las fuentes consultadas apuntan a un movimiento estratégico para anticiparse a iniciativas de corte general que puedan provenir de otras partes del Mediterráneo. La presencia secular y ahora masiva de esta planta y las formas peculiares de su cultivo y la fama mundial de sus utilidades ${ }^{18}$ son las razones que, hasta ahora, alientan la búsqueda de aquellos valores universales que mejor puedan justificar su inclusión. Ahora bien, en nuestra opinión este proceso, que por otra parte resultará largo y proceloso, debería partir del propósito de una gestión más sostenible del cultivo y, por ende, de los territorios en los que se asienta. Demasiado a menudo se escuchan frases felices que califican al olivar como bosque humanizado, con elevados valores ambientales resultado de una idónea relación entre el hombre y la naturaleza ${ }^{19}$. La realidad, a día de hoy, es muy diferente de esta idílica forma de ver las cosas, aunque es bien cierto que podrían alcanzarse buenos equilibrios ecológicos, económicos y sociales. De hecho, contamos con ejemplos de escala local que pudieran ser tomados como referencias de buenas prácticas. Y, por descontado, también es previsible que esta iniciativa se encuentre con importantes incomprensiones y rechazos cuando se sea consciente de que la inclusión implica unos modelos de gestión y unas normas de conservación que no se compadecen con los planteamientos productivistas que hoy son predominantes en el sector.

16 Valga como ejemplo la Candidatura para Patrimonio Mundial del Paisaje Cultural del Vino y el Viñedo de Rioja y Rioja Alavesa. https://paisajeculturaldelvino.wordpress.com (acceso 02-12-2014).

17 http://www.dipujaen.es/temas/tematica5 (acceso de 09-07-2014).

18 En particular, el vino y el aceite pueden considerarse como una esencia embotellada de la mediterraneidad, de la que se puede disfrutar (no solo en términos materiales sino también por las profundas evocaciones simbólicas que conlleva) en cualquier momento y lugar del mundo.

19 Para resaltar su aportación en el terreno de los bienes públicos se retrata (sin que sean esgrimidos argumentos justificativos de ninguna clase) como un agrosistema de alto valor medioambiental y un importante sumidero de $\mathrm{CO}_{2}$. 
Una buena manera de mostrar la valía de esta candidatura sería empezar por identificar bienes y valores del olivar susceptibles de protección, así como elaborar un plan de gestión y conservación con carácter localizado y experimental, que pudiera servir de banco de pruebas de los niveles de exigencia y participación que se requieren para llevar a buen puerto una iniciativa de este calibre. En este contexto, considerando que son valores excepcionales y universales los que se necesitan reconocer para tener ciertas garantías de éxito, nos parece que lo primero sería desterrar los discursos acríticos y poner en marcha acuerdos territoriales tendentes a superar las bases de insostenibilidad que ahora recorren la médula espinal del olivar y los territorios especializados en su cultivo, como indicamos en su momento (Delgado Cabeza, 2014).

\section{Ortofoto 1 \\ MOSAICO DE OLIVAR Y PINAR EN LA SIERRA DE SEGURA}

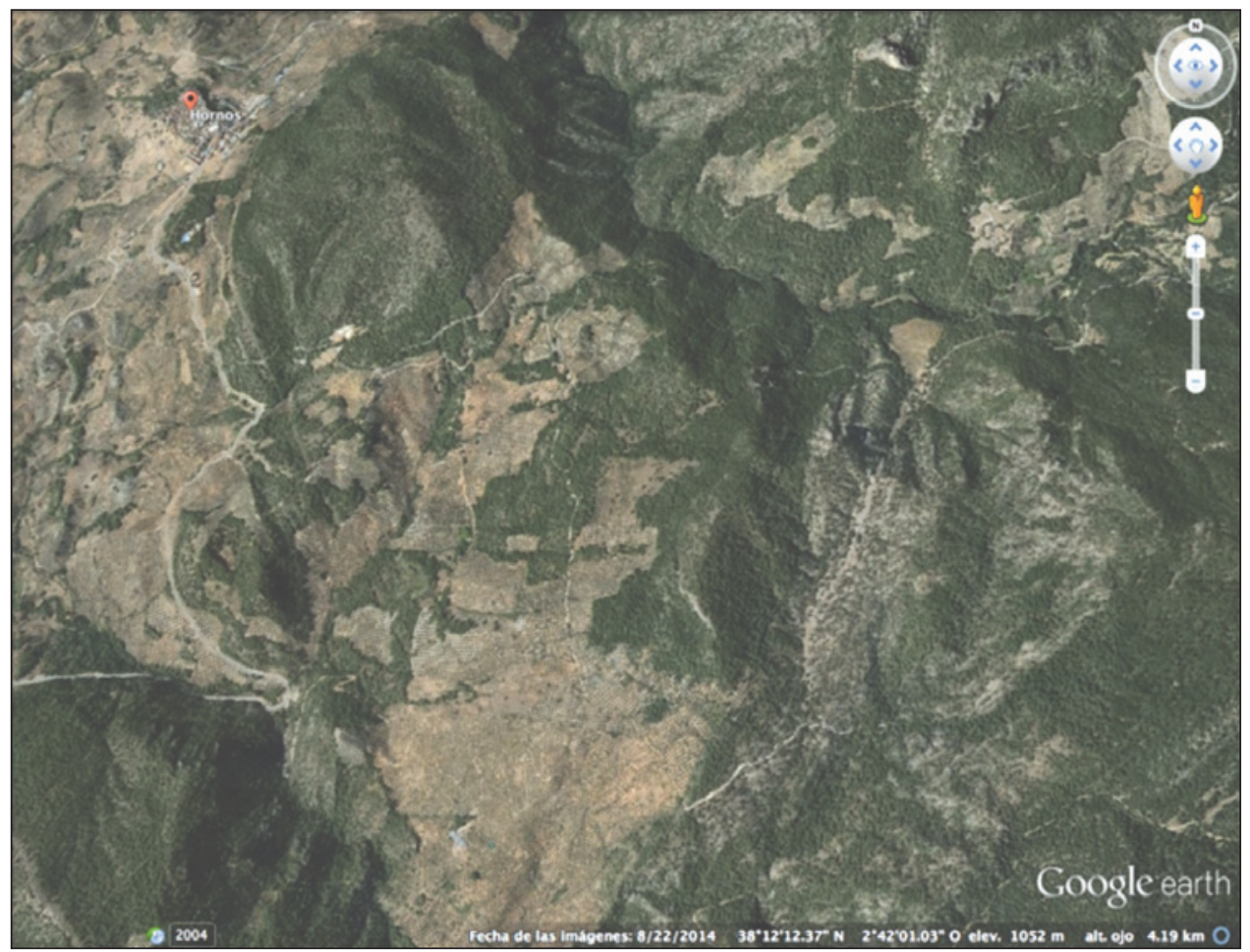

Fuente: https://www.google.es/intl/es/earth/index.html

Debemos, en este punto, volver de nuevo a los primeros epígrafes de este trabajo para recordar el largo proceso de formación del monocultivo y la diversidad de sistemas agrarios que comparten la mancha olivarera. Pues, a nuestro entender, otro trabajo previo de gran importancia es la selección de aquellos olivares que mejor se puedan adecuar a los valores excepcionales y universales a considerar. 
De entrada, habría que comenzar buscando en los olivares de sierra, allí donde la continuidad de la población fijada al territorio por el cultivo tiene más riesgo y donde se han desarrollado algunas de las técnicas más inteligentes de control de la erosión o aprovechamiento óptimo de los recursos hídricos; pero también donde se puede reconocer un mayor apego a la tierra (que va más allá desde luego que la mera cuenta de resultados que se pueda obtener de cualquiera de estas explotaciones agrícolas) de la población, pues no hay que olvidar que se trata en muchos casos de la primera y única opción que tuvieron las clases sociales más modestas de acceder a la propiedad (y con ello a una fuente alimenticia segura e independiente); imitando así, aunque fuera a pequeña escala y en terrenos de gran exigencia la estrategia reproductiva, lo que a las minorías terratenientes llevaban haciendo durante centurias. Son «olivares populares», minifundios humildes en términos económicos, pero cuidados con esmero y generadores de paisajes destacados cuando se dan los estímulos adecuados para los descendientes de los miles de neopropietarios que fueron haciéndose con estas parcelas a lo largo de los siglos XIX y XX (Infante-Amate, 2012b). Una posibilidad, por cierto, que puede ser favorecida por la firma de contratos territoriales en zonas rurales de acuerdo con normativa nacional y regional (Colombo y Camacho-Castillo, 2014).

Se trata, a veces, de terrenos cultivados en las inmediaciones e incluso el interior de áreas protegidas y pertenecientes a zonas acogidas a identificación geográfica protegida (D.O.P. de Sierra de Segura, Sierra de Cazorla y Sierra Mágina) por la diferenciación de sus aceites y a menudo con interesantes experiencias de producción ecológica (Sanz, García y Barneo, 2013). Es aquí, sin que ello signifique menospreciar la acumulación de cultura agraria tradicional que se ha producido en zonas de campiña y en propiedades de mayor dimensión, donde quizá haya que concentrar el esfuerzo de delimitación de las áreas de mayor interés (véanse fotos 5 y 6 y ortofotos 1 y 2). Por ejemplo, de los 17 Lugares de Interés Comunitario de la red europea Natura 2000 que se han reconocido en la provincia de Jaén (Mapa 1) la mayoría de ellos (salvo los que se componen de tramos fluviales) presentan diferentes porciones ocupadas por olivos. Como caso paradigmático se puede citar el denominado «Estribaciones de Sierra Mágina» (6.153 ha). Se trata de una prolongación del Parque Natural de igual denominación cubierta de olivares y lo interesante del caso es que desde una perspectiva conservacionista acumula una amplia biodiversidad que, no obstante, se entiende vulnerable por los medios que ocupa el cultivo (fuertes pendientes), las perspectivas de nuevas expansiones a costa de terrenos de vocación forestal y, por descontado, la existencia de prácticas agrícolas agresivas ${ }^{20}$. Esta es una prueba, en definitiva, del reto que supone la gestión no contradictoria entre conservación y desarrollo del olivar y que, insistimos, se nos antoja problema a resolver con antelación a cualquier intento serio de conseguir la declaración de paisaje de interés cultural.

20 http://www.juntadeandalucia.es/medioambiente/portal_web (acceso 02-12-2014). 
Foto 5

OLIVAR DE SIERRA (JAÉN). DETALLE DE LA ORTOFOTO 2

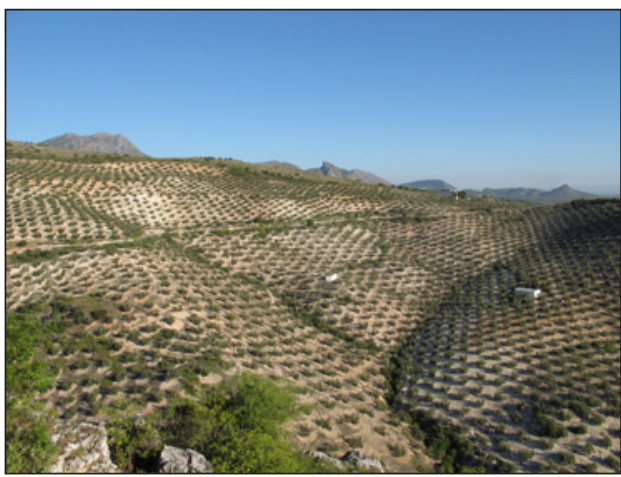

Fotografías de los autores.
Foto 6 MOSAICO DE OLIVAR Y PINAR (HORNOS). DETALLE DE LA ORTOFOTO 1

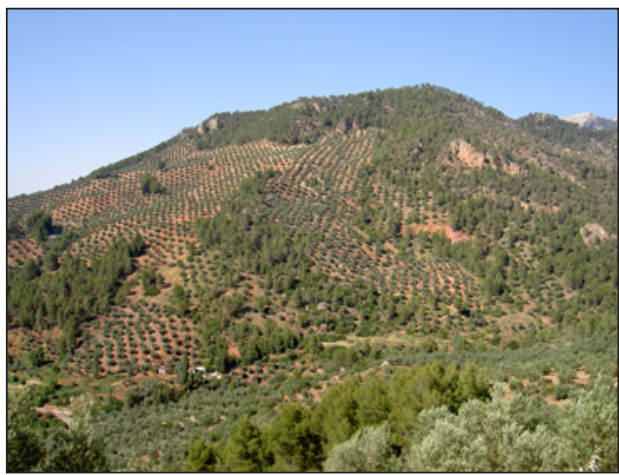

Ortofoto 2

OLIVAR EN LA SIERRA SUR DE JAÉN

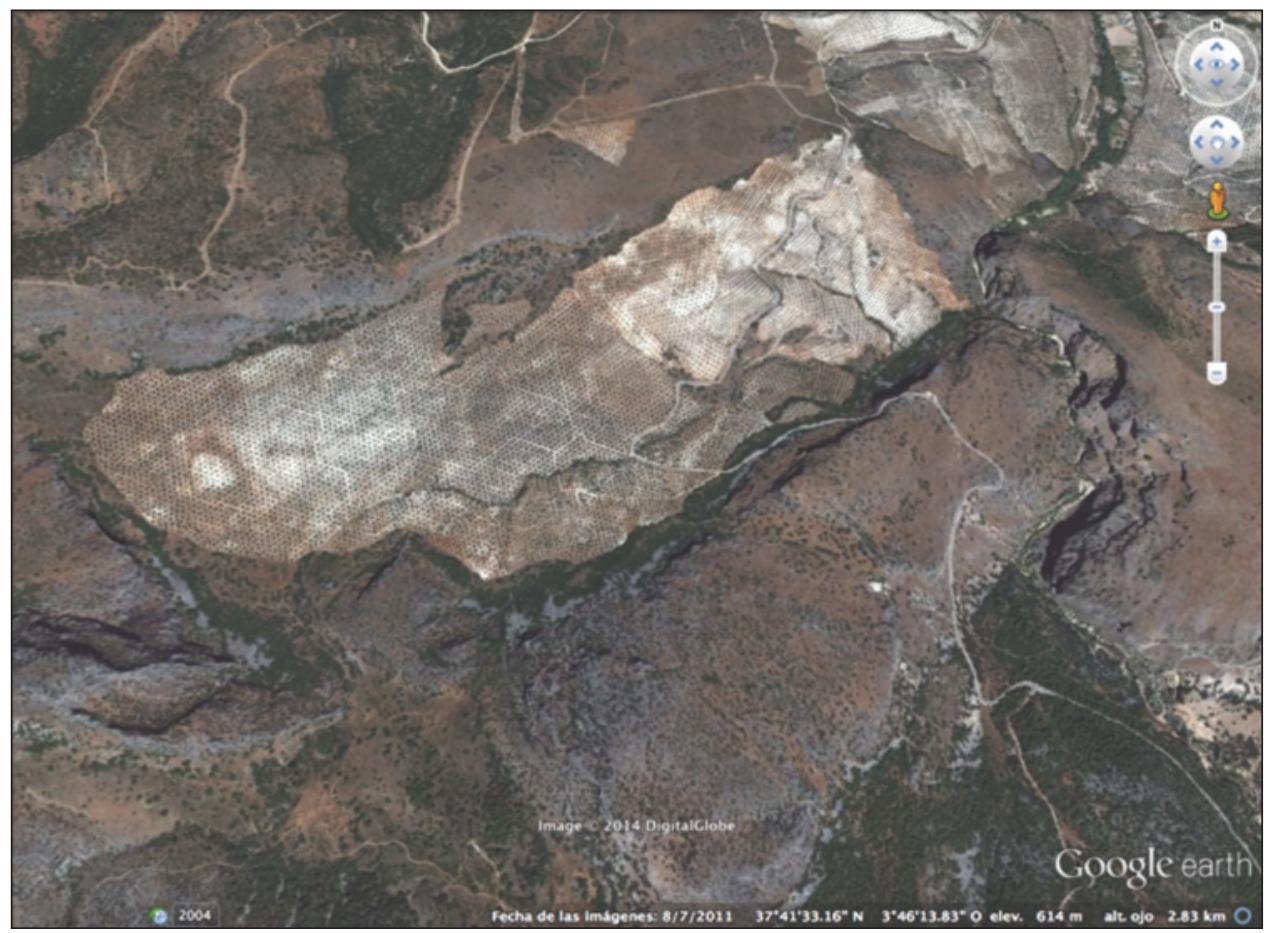

Fuente: https://www.google.es/intl/es/earth/index.html 


\section{Mapa 1 \\ OLIVARES EN EL INTERIOR DE LUGARES DE INTERÉS COMUNITARIO DE LA PROVINCIA DE JAÉN}

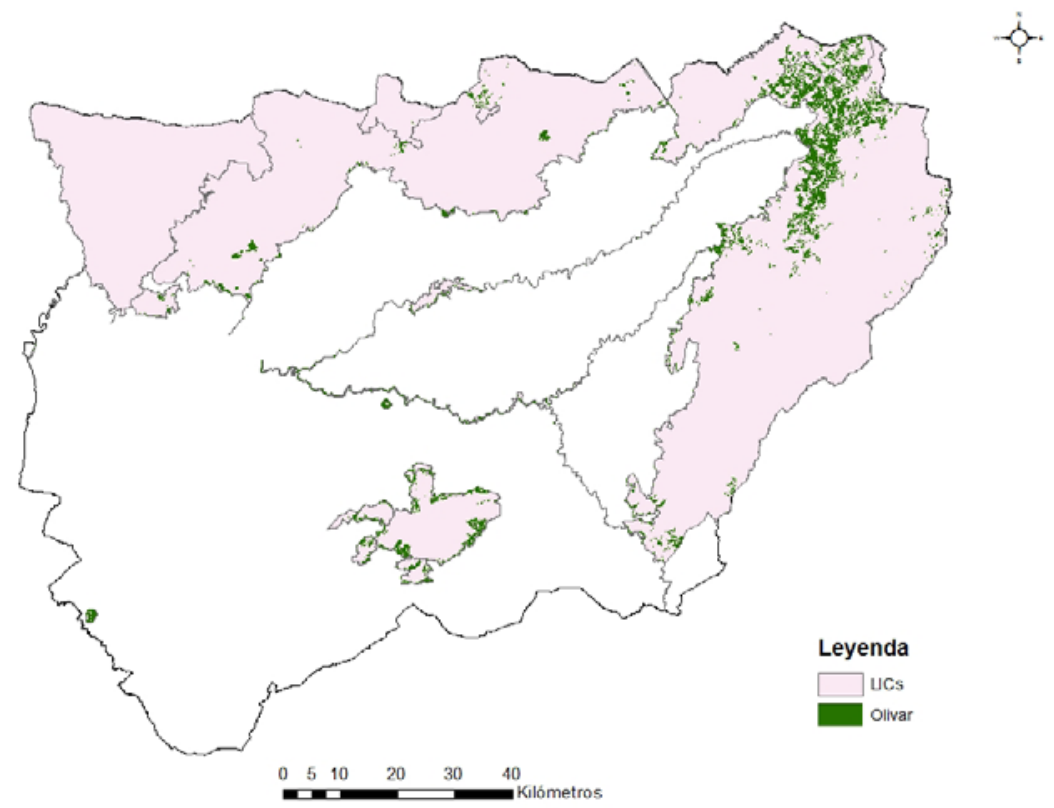

Fuente: Consejería de Medio Ambiente de la Junta de Andalucía.

\section{AGRADECIMIENTOS}

Este trabajo se enmarca en el Proyecto de Investigación de Excelencia «Caracterización y perspectivas del monocultivo olivarero jiennense: conformación espacio-temporal, diversidad paisajístico-agronómica y dinámicas territoriales inmediatas», financiado por la Consejería de Economía, Innovación y Ciencia de la Junta de Andalucía (SEJ - 1153, convocatoria 2012).

\section{BIBLIOGRAFÍA}

AMAYA CORCHUELO, S. (2010) (Coord.): Catálogo del patrimonio oleícola. http://www.patrimonioleicola.com/documentos/publi1.pdf (acceso 30/09/2014).

ANGLÉS, S. (2009): «La diversité des paysages oléicoles: morphologie, valoristaion et perspectives (Sierra Mágina, Baronnies»). En VV. AA.: El olivar: paisaje, patrimonio $y$ desarrollo sostenible. Jaén. ADR Sierra Mágina, pp. 57-73.

ANTA FÉLEZ, J.L. (2002): «Parentesco y economía en una sociedad giennense», en Anta, J.L.; Palacios, J. (Edit.): La Cultura del Aceite en Andalucía. Sevilla. Fundación Machado, pp. 159-170. 
ANTA FÉLEZ, J.L. (2005): «El árbol es masculino: economías, géneros y cambios en el olivar giennense». En Anta, J. L., Palacios, J. y Guerrero, F.(Eds.): La cultura del olivo. Ecología e economía, sociedad. Jaén. Servicio de Publicaciones de la Universidad de Jaén, pp. 131-158.

ARAQUE, E.; GALLEGO, V.J. y SÁNCHEZ, J.D. (2002): «El olivar regado en la provincia de Jaén». Investigaciones Geográficas, n 28, pp. 5-32.

CASTILLO RUIZ, J. (2009): «La dimensión territorial del patrimonio histórico». En Castillo, J.; Cejudo, E. y Ortega, A. (Eds.): Patrimonio Histórico y Desarrollo Territorial. Universidad Internacional de Andalucía. Sevilla, pp. 27-48.

CASTILLO RUIZ, J. y MARTÍNEZ YÁNEZ, C. (2014): «El Patrimonio Agrario: definición, caracterización y representatividad en el ámbito de la UNESCO». Boletín de la Asociación de Geógrafos Españoles, n 66, pp. 105-124.

CEJUDO GARCÍA, E. y MAROTO MARTOS, J.C. (1990): «Ocultación y variaciones superficiales en la provincia de Jaén en el tercer cuarto del siglo XIX». Cuadernos Geográficos de la Universidad de Granada, n 18-19, pp. 149-172.

COBO DE GUZMÁN, F. (2005): «Imágenes, desechos, espejismos. Las sociedades rurales del olivar y la (re)producción cultural del mercado». En Anta, J. L., Palacios, J. y Guerrero, F.(eds.): La cultura del olivo. Ecología, economía, sociedad. Jaén. Servicio de Publicaciones de la Universidad de Jaén, pp. 159-176.

COLOMBO, S. y CAMACHO-CASTILLO, J. (2014): «Caracterización del olivar de montaña andaluz para la implementación de los Contratos Territoriales de Zona Rural». Información Técnica Económica Agraria, no 110 (3), pp. 282-299.

CORTÉS, J. (1995): El Corán. Traducción y notas Julio Cortés; intr. e índice Jacques Jomier, $5^{\text {a }}$ ed. rev. Barcelona, Herder.

DELGADO CABEZA, M. (2014): «La globalización de la agricultura andaluza. Evolución y vigencia de la cuestión agraria en Andalucía». En González de Molina, M. (coord.): La cuestión agraria en la historia de Andalucía. Sevilla. Centro de Estudios Andaluces, pp. 97-132.

DIRECCIÓN GENERAL DE AGRICULTURA, INDUSTRIA Y COMERCIO (1891): Avance estadístico sobre cultivo y producción del olivo en España formado por la Junta Consultiva Agronómica en 1888. Madrid. Tipolitografía de L. Péant e Hijos.

DIRECCIÓN GENERAL DEL INSTITUTO GEOGRÁFICO Y ESTADÍSTICO (1888): Reseña geográfico-estadística de España. Madrid.

FEO PARRONDO, F. (2002): «El Catastro y otras fuentes complementarias para el estudio de la propiedad rústica española (1800-1940)». CT Catastro, n ${ }^{\circ} 44$, pp. 89-101.

FERNÁNDEZ SALINAS, V. y SILVA PÉREZ, R. (2015): «Paisajes españoles susceptibles de ser incluidos en la Lista del Patrimonio Mundial de UNESCO. Criterios para su identificación y selección». Boletín de la Asociación de Geógrafos Españoles, $\mathrm{n}^{\circ}$ 68, pp. 253-278.

GALLEGO SIMÓN, V.J. (2014): Colonización y regadíos en el Sur de España. El caso particular de la provincia de Jaén. Madrid. Ministerio de Agricultura, Alimentación y Medio Ambiente.

GARRIDO GONZÁLEZ, L. (2005): Olivar y cultura del aceite en la Historia de Jaén. Jaén. Instituto de Estudios Giennenses. 
GUERRERO GARCÍA, A. (2003): Nueva olivicultura. Madrid. Ediciones Mundi-Prensa. GUZMÁN ÁLVAREZ, J.R. (2007): «El palimpsesto cultivado. Propuesta de un catálogo de paisajes culturales históricos del olivar andaluz». En VV. AA.: I Congreso de la cultura del olivo. Jaén. Instituto de Estudios Giennenses, pp. 637-694.

GUZMÁN ÁllVAREZ, J. R. y ZOIDO NARANJO, F. (2013): «El olivar andaluz en su dimensión paisajística. Espacio vivido y espacio sentido». En VV. AA.: Andalucía. El olivar. Sevilla. Grupo de Estudios Avanzados sobre Territorio y Medio Ambiente, pp. 63-81.

HERNÁNDEZ ARMENTEROS, S. (2001): «Empresas y empresarios españoles en la exportación de aceite de oliva, 1900-1936. Especial referencia al mercado noruego de conservas de pescado». Revista de Historia Económica, no 19 (2), pp. 383-414.

INFANTE-AMATE, J. (2012): El carácter de la especialización olivarera en el sur de España (1750-1930). Ecología, campesinado e Historia. Sociedad Española de Historia Agraria. Documentos de Trabajo (acceso 02/05/2012).

http://repositori.uji.es/xmlui/bitstream/handle/10234/29950/DT-12-01.pdf?sequence=1

INFANTE-AMATE (2012b): «Cuántos siglos de aceituna. El carácter de la expansión olivarera en el sur de España (1750-1900)». Revista de Historia Agraria, no 58, pp. 39-72.

INSTITUTO NACIONAL DE ESTADÍSTICA (1956): Reseña estadística de la provincia de Jaén. Madrid.

JIMÉNEZ SÁNCHEZ, A. (1997): «La Organización Común de Mercado del aceite de oliva: instrumentos de regulación». En Parras Rosa, M. (Coord.): La reforma de la OCM y el futuro del olivar. Jaén. Servicio de Publicaciones de la Universidad y Universidad Internacional de Andalucía, pp. 297-330.

LÓPEZ PALOMEQUE, F. y FONT URGELL, X. (2014): «Gestión pública del turismo en los espacios de interior en España: el papel de las diputaciones provinciales».

http://coloquioturismo.com/debate_2.pdf (acceso de 03-12-2014).

MATA OLMO, R. y MUÑOZ DUEÑAS, M.D. (1999): «Fuentes y práctica catastral en Córdoba (siglos XVIII-XX). Una reflexión desde la historia agraria». Revista de Estudios Agrosociales y Pesqueros, $\mathrm{n}^{\circ}$ 185, pp. 81-107.

MINISTERIO DE AGRICULTURA (1975): Inventario agronómico del olivar. Provincia de Jaén. Madrid. Dirección General de la Producción Agraria.

MORAL PAJARES, E., SÁNCHEZ MARTÍNEZ, J. D. et al. (2014): «Recursos locales y competitividad global: la exportación de aceite de oliva virgen en Andalucía». Boletín de la Asociación de Geógrafos Españoles, nº 66, pp. 539-558.

NAREDO PÉREZ, J.M. (1983): «La crisis del olivar tradicional como cultivo biológico». Agricultura y Sociedad, $\mathrm{n}^{\circ}$ 26, pp. 168-288.

ORTEGA RUIZ, A. (2010): «La mirada territorial: el patrimonio rural y su valoración». En López Guzmán, R. (Coord.): Patrimonio Histórico: retos, miradas, asociaciones e industrias culturales. Universidad Internacional de Andalucía. Sevilla, pp. 118-146.

PALACIOS RAMÍREZ, J. (2002): «Una lectura simbólica del olivo: (de) construir identidades». Sumuntan. Revista de Estudios de Sierra Mágina, n 17, pp. 69-76.

PALACIOS RAMÍREZ, J. (2005): «Notas sobre el olivar en Jaén desde una perspectiva económico-política». En Anta, J. L., Palacios, J. y Guerrero, F.(Eds.): La cultura del olivo. Ecología, economía, sociedad. Jaén. Servicio de Publicaciones de la Universidad de Jaén, pp. 101-130 
REMESAL RODRÍGUEZ, J. (2007): «La cultura del aceite de oliva en la cuenca mediterránea: el caso de la Bética». http://ceipac.gh.ub.es/infos/Data/expoliva.pdf (acceso 04-12-2014).

RODRÍGUEZ MOLINA, J. (1989): «Inicios de la expansión del olivar en Jaén. Andújar (1477-1515). En VV. AA.: Estudios: Homenaje al profesor Alfonso Sancho Sáez. Granada. Servicio de Publicaciones de la Universidad de Granada, tomo I, pp. 275-286.

ROJAS SOLA, J. I. y GARCÍA HORNOS, J. L. (2007): «Estado actual de los museos y centros de interpretación de la cultura del olivar y el aceite de oliva: propuesta de mejora». En VV. AA.: I Congreso de la Cultura del Olivo. Jaén. Diputación Provincial de Jaén, pp. 245-252.

RUIZ ORTEGA, J. L. (2004): «Patrimonio y desarrollo local en Andalucía». Boletín de la Asociación de Geógrafos Españoles, no 38, pp. 101-114.

SÁNCHEZ, J. D.; GALLEGO, V.J. y ARAQUE, E. (2011): «El olivar andaluz y sus transformaciones recientes. Estudios Geográficos, n ${ }^{\circ} 270$, pp. 203-229.

SÁNCHEZ MARTÍNEZ, J.D. y GALLEGO SIMÓN, V.J. (2011): «La nueva reconversión productiva del olivar jiennense: aproximación inicial a sus fundamentos y limitaciones». Cuadernos Geográficos de la Universidad de Granada, n 49, pp. 95-122.

SÁNCHEZ SALAZAR, F. (1989): «El olivo y su expansión en el Reino de Jaén durante el siglo XVIII». Boletín del Instituto de Estudios Giennenses, n ${ }^{\circ} 138$, pp. 83-96.

SANZ CAÑADA, J.; GARCÍA BRENES, M.D. y BARNEO ALCÁNTARA, M. (2013): El aceite de oliva de montaña en Jaén: calidad y cadena de valor (acceso de 02-12-2014).

http://digital.csic.es/bitstream/10261/90567/1/Tender\%20Olivar\%20Montaña\%20Jaén_ Sanz_GBrenes_Barneo_2013.pdf

SILVA PÉREZ, R. (2008): «Hacia una valoración patrimonial de la agricultura». Scripta Nova. Revista Electrónica de Geografía y Ciencias Sociales. Vol. XII, núm. 275.http:// www.ub.edu/geocrit/sn/sn-275.htm (acceso 02-04-2013)

SILVA PÉREZ, R. (2009): «Agricultura, paisaje y patrimonio territorial. Los paisajes de la agricultura vistos como patrimonio». Boletín de la Asociación de Geógrafos Españoles, $\mathrm{n}^{\circ} 49$, pp. 309-334.

TORRES, F. (1998): Historia de Baeza. Estudio y edición de José Rodríguez Molina. Ayuntamiento de Baeza.

TROITIÑO-TORRALBA, L. (2014): «Aproximación a la dimensión turística del paisaje del olivar en el sistema territorial español». http://coloquioturismo.com/debate_2.pdf (acceso de 03-12-2014).

UNIVERSIDAD INTERNACIONAL DE ANDALUCÍA (2013): Carta de Baeza sobre Patrimonio Agrario. Sevilla.

ZAMBRANA PINEDA, J.F. (1987): Crisis y modernización del olivar español (18701930). Madrid. Ministerio de Agricultura, Pesca y Alimentación. 